\title{
A pesquisa tipológica em línguas indígenas brasileiras
}

\author{
The typological research in Brazilian indigenous languages \\ Camille Cardoso MIRANDA* \\ Universidade Estadual de Campinas (UNICAMP) \\ Fabíola Azevedo BARAÚNA** \\ Universidade Federal do Pará (UFPA)
}

RESUMO: O foco do presente artigo é discutir alguns aspectos tipológicos importantes de línguas indígenas brasileiras, principalmente em relação aos aspectos fonológicos. Utilizamos dois fenômenos fonológicos bastante comuns em línguas naturais: nasalização e palatalização. Para nasalização utilizamos três línguas que pertencem à família Tupí-Guaraní (Parakanã, Mbyá e Guajá) e para o fenômeno de palatalização utilizamos três línguas da família Aruák (Mehináku, Palikur e Paresi). O objetivo é discutir a importância da pesquisa tipológica e fonológica em línguas geneticamente semelhantes, como também verificar os padrões de nasalidade e palatalização para postular possíveis generalizações e especificidades que possam contribuir, posteriormente, para a constatação de tendências e padrões em línguas indígenas brasileiras. Um resultado geral desse estudo mostra que mesmo em línguas relacionadas existem diferentes padrões no que diz respeito aos fenômenos estudados que podem contribui com os estudos translinguisticos que verifica não apenas as similaridades, mas também as diferenças encontradas nos fenômenos linguísticos nas línguas do mundo.

PALAVRAS-CHAVE: Tipologia linguística. Nasalização e Palatalização. Línguas indígenas brasileiras.

ABSTRACT: The focus of the present paper is to discuss some important typological aspects of Brazilian indigenous languages, mainly regarding the phonological aspects. We use two phonological phenomena quite commons on nature languages: nasalization and palatalization. For nasalization we use three languages that belongs to the Tupi-Guarani family (Parakanã, Mbyá and Guajá) and for the phenomenon of palatalization we use three languages of the Arawak family (Mehinaku, Palikur and Paresi). The aim is to discuss the importance of typology and phonology research as well to verify the patterns of nasalization and palatalization

\footnotetext{
*Doutoranda em Linguística pela Universidade Estadual de Campinas (UNICAMP). Possui mestrado em Estudos Linguísticos pela Universidade Federal do Pará. Bolsista FAPESP (nº processo 2018/18072-1) Email para contato: camiranda126@gmail.com

** Doutoranda em Estudos Linguísticos pela Universidade Federal do Pará. Possui mestrado pela mesma instituição, Bolsista de Doutorado CAPES. E-mail para contato: fabiolabarauna@hotmail.com
} 
for possible generalizations that might point to some trends and patterns in Brazilian indigenous languages. A general result of this study shows that even in related languages there are different patterns with regarding to the studied phenomena, contributing with the translinguistic studies that verify not only the similarities but also the differences found of linguistic phenomena in the languages of the world.

KEYWORDS: Linguistic Typology. Nasalization. Palatalization. Brazilian indigenous languages.

\section{Introdução}

O presente trabalho tem como objetivo evidenciar e discutir a pesquisa tipológica em línguas indígenas brasileiras, focando principalmente nos aspectos fonológicos de assimilação, nasalização e palatalização, a partir de uma amostra preliminar de seis línguas indígenas brasileiras de duas grandes famílias Tupí-Guaraní e Aruák. Os materiais utilizados para a análise partem da compilação dos estudos destas línguas, dentre teses, dissertações e artigos. Desse modo, o objetivo desse trabalho é discutir a importância da tipologia linguística e fonológica nos estudos de línguas indígenas brasileiras.

Para Croft (2002), o termo tipologia tem um número de diferentes usos, tanto na linguística quanto em outras áreas. Para o autor, a definição mais comum do termo é aproximadamente semelhante com "taxonomia" ou "classificação" (CROFT, 2002). Assim sendo, a definição mais ampla de tipologia refere-se "à classificação de tipos estruturais entre as línguas" (CROFT, 2002, p.1). Esses estudos vão desempenhar um importante papel na linguística moderna, por exemplo, com a tipologia podemos verificar até que ponto um aspecto linguístico pode estar presente praticamente em todas as línguas e, a partir destes padrões semelhantes, postular universais linguísticos, ou, ao contrário tendências universais.

Conforme Comrie (1989) as pesquisas sobre universais linguísticos estão mais interessadas nas propriedades que são comuns a todas as línguas do mundo, enquanto que a tipologia linguística está mais concentrada nas variações que essas línguas podem ter. No entanto, o autor adverte que linguistas que se interessam por pesquisas relacionadas aos universais linguísticos também estão interessados em linguística tipológica. Desse modo, é praticamente impossível isolar um estudo do outro, pois 
ambos se interessam por variações de fenômenos linguísticos nas línguas do mundo. Em relação às línguas indígenas brasileiras podemos verificar alguns sobrevoos tipológicos em relação às propriedades morfossintáticas, contudo, em relação à fonologia, os estudos tipológicos ainda necessitam ser mais discutidos e analisados nessas línguas.

Sabemos que o Brasil é um país que possui bastante diversidade linguística, o número de línguas faladas no território brasileiro não é um consenso exato. Rodrigues (2013) registra 199 línguas indígenas, enquanto que Moore et tal (2008) afirmam que “ embora venha sendo repetido com frequência que 180 é o número de línguas indígenas brasileiras, pelo critério de inteligibilidade mutúa, a soma dificilmente utrapassa 150" (MOORE et al, 2008, p. 38). Já os dados do IBGE de 2010 (Insituto Brasileiro de Geografia e Estatística) contabilizam pelo menos 274 línguas indígenas, faladas por, aproximadamente, 900 mil índios no Brasil. Todavia, embora não se tenha um número exato de quantas línguas são faladas no território brasileiro, é importante mencionar que as línguas indígenas brasileiras estão em situações de alto risco. De acordo com Moore et al (2008), as línguas indígenas brasileiras estão desaparecendo muito rápido, muitas delas sem qualquer tipo de documentação. Os autores elucidam que uma boa parte das línguas mais ameaçadas, são também aquelas menos estudadas ou documentadas.

Diante desse cenário, é importante desenvolver cada vez mais estudos linguísticos referentes às línguas indígenas brasileiras, visto que a maioria delas se encontra em perigo de extinção. Desse modo, o propósito do artigo não é apenas discutir e compreender a pesquisa tipológica, mas também analisar tais aspectos em línguas indígenas brasileiras, com a finalidade de promover mais estudos relacionados a essas línguas como também aprofundar os conhecimentos de processos fonológicos como a assimilação em línguas naturais.

\section{Tipologia Linguística}

Para Whaley (1997, p.7) a definição de tipologia na linguística é "a classificação das línguas ou dos componentes linguísticos da língua baseada nas características formais compartilhadas". O autor explica que a tipologia tem como objeto de identificação os padrões translinguísticos e as correlações entre esses padrões. O autor aponta que as metodologias e os resultados obtidos em uma pesquisa tipológica são em princípio compatíveis com qualquer teoria gramatical. Whaley $(1997$, p.7) dá três 
significados proposicionais que embalam a definição de tipologia, são eles: (i) a tipologia utiliza comparações translinguísticas; (ii) a tipologia classifica línguas ou aspectos linguísticos e; (iii) tipologia examina traços formais da língua.

A abordagem tipológica se interessa pela classificação das línguas ou componentes linguísticos que podem ser recorrentes ou raros. Desse modo, usando dados translinguísticos, é possível estabelecer diferentes fenômenos que podem ser mais comuns ou raros nas línguas naturais. Para Whaley (1997), uma pesquisa tipológica é melhor compreendida quando há identificação de graus de similaridades e variedades entre as línguas. Para Croft (2002) a tipologia é o estudo de padrões que ocorrem sistematicamente em línguas naturais. Ele a define como "tipologia generalizada". Desse modo, os padrões encontrados em tipologia generalizada são universais linguísticos. O autor informa que tipologia deste tipo iniciou-se com Joseph $\mathrm{H}$. Greenberg (1963) que descobriu implicações universais da morfologia e ordem de palavras em línguas naturais.

Körtvélyessy (2017) afirma que a linguística tipológica não trata somente de traços tipologicamente compartilhados, mas também de traços universalmente compartilhados, denominados de universais linguísticos. Como já mencionamos, os estudos de teor tipológico são praticamente recentes na teoria linguística em geral. Em relação às línguas indígenas brasileiras, esses estudos ainda são mais raros, principalmente em se tratando de tipologia fonológica. No entanto, embora seja um estudo recente, a tipologia linguística é uma área de estudo muito importante para os estudos linguísticos e contribui bastante para verificar os fenômenos linguísticos mais ou menos recorrentes encontrados nas línguas do mundo.

De acordo com Whaley (1997) todas as pesquisas tipológicas envolvem comparações entre línguas. Por exemplo, o que se propõe neste artigo é uma comparação sobre os processos de nasalização e palatalização entre as línguas da família Tupí-Guaraní e Aruák, porém, esta comparação poderia também ser realizada com línguas que não tenham nenhum tipo de relação genética, mas que podem compartilhar um determinado aspecto. É interessante verificar que embora essas línguas sejam geneticamente semelhantes, elas apresentam similaridades e variações nos fenômenos estudados. Desse modo, nota-se a importância de um estudo tipológico de línguas geneticamente relacionadas, uma vez que ao verificar tais padrões podemos compreender as relações entre as semelhanças e também as diferenças tipológicas encontradas em línguas que pertencem em uma mesma família linguística. 


\section{Tipologia Fonológica}

Gordon (2016) afirma que uma linha de pesquisa tipológica dentro da fonologia envolve a definição de padrões translinguísticos e a frequência relativa desses padrões na análise tipológica. As pesquisas de fonologia na tipologia linguística exigem um grande número de dados, para que assim possa-se obter os padrões que são mais generalizados e aqueles que são menos comuns. A tipologia fonológica, embora tenha sido estudada por alguns autores, infelizmente tem recebido menos atenção do que as pesquisas no âmbito da morfologia ou sintaxe dentro de um modelo tipológico (GORDON, 2016). Hyman (2014) observou que muitos estudos de teor tipológico são centrados em torno da morfossintaxe, enquanto a fonologia tem sido uma transição de um campo descritivo/analítico para um campo experimental. Dessa forma, desde o início dos estudos tipológicos, até mesmo os mais atuais, tendem para uma tipologia que envolve propriedades morfossintáticas, enquanto que aspectos fonológicos ainda são estudos que necessitam ser mais consolidados ${ }^{1}$.

As comparações translinguísticas em estudos fonológicos são também frequentemente empregadas em estudos de inventários segmentais nas línguas naturais. Odden (2013) observou que alguns segmentos são mais frequentes na maior parte das línguas do mundo do que outros. Essas comparações são observadas no estudo de marcação que segundo Odden (2013, p.235) é a ideia de que "nem todos os segmentos ou grupos de segmentos têm status iguais em sistemas fonológicos e isso leva à relação implicacional”. Para exemplificar a relação implicacional, Odden (2013) dá como exemplo a relação entre sistemas vocálicos orais e nasais. O autor explica que muitas línguas têm somente vogais orais e muitas outras têm tanto vogais orais como nasais. Porém, não há línguas que tenham somente vogais nasais. A existência de vogais nasais vai implicar a existência de vogais orais.

Vadja (2001), ao tratar de tipologia fonológica, define-a como a comparação de

\footnotetext{
${ }^{1}$ Em relaçao aos estudos de tipologia fonologica, Hyman (2014) expõe uma série de estudos de Greenberg: estrutura de sílaba (GREENBERG, 1962, 1978), características distintivas (GREENBERG, JENKINS; FOSS, 1967), harmonia vocálica (GREENBERG, 1963b), outro referente às vogais nasalizadas (GREENBERG, 1966), há ainda sobre consoantes glotalizadas (GREENBERG, 1970), sistemas prosódicos das palavras (GREENBERG;KASCHUBE, 1976), reconstrução fonológica de línguas africanas (GREENBERG, 1948). E dentro desses trabalhos podemos acrescentar uns mais recentes tais como: Typology of Phonological Systems, de Maddieson (2010); Patterns of Sound, de Maddieson (1984); How (not) to do phonological typology: the case of pitch-accent, de Hyman (2009),; The Internal structure of Nasal-Stop Sequence: Evidence from Autronesian, de Cohn e Riehl (2008), e The phonetic roots of phonological typology: Final syllable vowels, de Barnes (2003), Hierarchial opacity effects in Nasal Harmony, de Walker (1998),
} 
línguas considerando o número ou os tipos de sons que elas possuem. Para o autor, o inventário de fonemas de qualquer língua se altera apenas ao longo do tempo, diferentemente do vocabulário, ao qual novas palavras são constantemente adicionadas. Por isso, como o número de fonemas das línguas é relativamente estático, é possível classificá-las de acordo com os fonemas que elas possuem. Os estudos desse tipo ajudam a compreender melhor a diversidade linguística e a elaborar generalizações sobre certas propriedades comuns e/ou divergentes de várias línguas. Ainda segundo Vajda, um aspecto importante da tipologia fonológica é classificar as línguas de acordo com o tipo de sons presentes ou ausentes. Alguns sons são raramente encontrados, enquanto outros estão quase sempre presentes nos inventários fonêmicos (Maddieson, 1984).

Lindblom e Maddieson (1988) a partir dos dados de 317 línguas do UPSID (Phonological Segment Inventory Database) observaram que as línguas do mundo tendem a ter $70 \%$ de sons obstruintes e $30 \%$ de sons sonorantes. No caso dos sons que estão presentes praticamente em todas as línguas, as obstruintes, principalmente as surdas, são um exemplo, pois são sons bastante comuns em pesquisas translinguísticas e não foram atestadas línguas em que esses sons estejam ausentes (VADJA, 2001). A tipologia fonológica também está presente em processos segmentais e prosódicos. De acordo com Odden (2013), a fonologia segmental se preocupa com os traços de um segmento e como eles podem afetar os traços de outros segmentos.

Desse modo, O conceito de tipologia fonológica dado por Hammond ( 2006, p.523) define a tipologia fonológica como "uma classificação de sistemas linguísticos baseada nas propriedades fonológicas". Para este autor existem quatro tipos básicos de tipologia: 1) areal ou genética; 2) tipologia baseada nas propriedades fonológicas superficiais; 3) tipologia baseada em algumas propriedades fonológicas subjacentes; e por último, 4) a tipologia paramétrica. Assim sendo, o estudo apresentado nesse artigo não se baseia apenas em propriedades fonológicas das línguas de análise, mas também em uma tipologia genética (tipo 1) já que se trata de línguas que fazem parte de uma família específica.

Podemos estudar a tipologia fonológica também em processos prosódicos que se baseia na estrutura da sílaba, do acento, do ritmo da palavra como tom, e também trata de fenômenos que se relacionam com a posição do segmento em uma linha fonológica, como é o caso da assimilação, um processo bastante comum nas línguas naturais e o que será explicado a seguir. 


\section{O processo de Assimilação: Exemplificando a tipologia nos fenômenos de nasalização e palatalização em línguas indígenas brasileiras}

Crystal (2000, p. 33) define a assimilação como o termo da fonética que referese "à influência exercida por segmento de som sobre a ARTICULAÇÃO de outro, de forma que os sons se tornem mais parecidos, ou mesmo idênticos". Conforme Baković (2007), o processo de assimilação pode ser dividido em dois tipos: Local e a Longa distância. Quando a assimilação é local, ela ocorre entre segmentos estritamente adjacentes, ou seja, a consoante ou a vogal vai assimilar seu traço apenas ao segmento que está antecedendo ou precedendo-a. Já a assimilação a longa distância ocorre não apenas em segmentos que estão estritamente adjacentes, mas sim naqueles que podem ser mais propícios a serem afetados pelo processo. A nasalização e palatalização são dois processos em línguas do mundo que atestam estes dois tipos de assimilação. Os dois fenômenos assimilatórios são descritos a seguir.

\subsection{Nasalização}

A nasalização é um estudo de interesse tanto da fonética quanto da fonologia. Cohn (1993) explica que dentro da fonética os estudos de nasalização estavam relacionados aos experimentos acústicos e percpetuais de vogais nasalizadas, enquanto que na fonologia, os estudos incluíam regras de espalhamento ou de tipologia de inventários de segmentos nasais em línguas do mundo (COHN, 1993). Conforme a definição de Crystal (2000), o termo nasal ou nasalizado é relacionado aos sons que são produzidos quando o véu palatino está abaixado, permitindo que o fluxo do ar passe pelo nariz; tanto as consoantes quanto as vogais podem ser articuladas desse modo.

Segundo as informações de Maddieson (2013) no site The World Atlas of Language Structures Online (http://wals.info/chapter/18 ), as consoantes nasais em inventários fonológicos são presentes em praticamente todas as línguas do mundo. Walker (1998) também enfatiza que quase todas as línguas (cerca de 97\%) têm segmentos nasais em seus inventários fonológicos; já em relação às vogais nasais, esse número é bastante desproporcional se compararmos com a porcentagem das consoantes 
nasais, uma vez que são apenas $25 \%$ das línguas do mundo exibindo vogais como fonemas nasais (WALKER, 1998).

Hajek (2013) realizou um trabalho cujo objetivo era verificar vogais nasais com valor distintivo. Cerca de um quarto da amostra do site WALS tem contraste entre vogais orais e nasais. Ou seja, sessenta e quatro línguas exibidas nesses dados tipológicos apresentam contraste entre vogais nasais e orais, enquanto 180 não têm esse contraste. De acordo com Hajek (2013), a nasalização não é um fenômeno restrito ao contraste entre vogais fonêmicas nasais e orais. $\mathrm{O}$ autor afirma que cerca das 180 línguas que não exibem contraste em $\mathrm{V} / \tilde{\mathrm{V}}$, pelo menos 30 são reportadas como tendo um tipo de nasalidade não fonêmica, nasalização contextual de vogal adjacente à consoante nasal (assimilação local). Em relação ao espalhamento da nasalidade, Hajek (2013) explica que vogais nasalizadas têm propriedades prosódicas diferentes entre as línguas. Em muitas línguas não há espalhamento de nasalização, no máximo uma nasalidade local, isto é, restrita; porém existem línguas cujas vogais nasalizadas inerentes podem espalhar o traço [nasal] para segmentos adjacentes compatíveis.

Walker (1998) afirma que os segmentos mais compatíveis com a nasalidade são as vogais, glides e líquidas enquanto as obstruintes são segmentos menos compatíveis, comportando-se como transparentes ou bloqueadoras do processo. Os segmentos bloqueadores são aqueles que permanecem orais e bloqueiam o espalhamento, já os segmentos transparentes são aqueles que resistem à nasalização, isto é, permanecem orais, mas permitem a continuação do espalhamento de nasalidade.

Em relação aos gatilhos, ou seja, aqueles segmentos que desencadeia a nasalidade, na maioria das línguas é uma consoante nasal subjacente, vogal nasal fonêmica e às vezes é um traço suprassegmental / /. A direcionalidade do espalhamento é um aspecto importante no que diz respeito à nasalidade. Esse espalhamento pode se dar de três formas: da direita para esquerda, o qual chamamos de espalhamento regressivo, da esquerda para direita, que se refere ao espalhamento progressivo e o espalhamento bidirecional que espalha para ambos os lados. Nas línguas de análise da família Tupí-Guaraní o espalhamento regressivo é o mais recorrente. Na subseção que segue discutiremos o processo de nasalidade em Parakanã, Mbyá e Guajá.

\subsection{Discussões dos dados do processo de nasalização Parakanã, Mbyá e Guajá (Tupí- Guaraní)}


Trataremos, nesta seção, o processo de nasalização em três línguas da família Tupí-Guaraní (Parakanã, Mbyá e Guajá). Iniciando a análise com a língua Parakanã. Essa língua tem como gatilho de nasalidade apenas consoantes fonologicamente nasais /m, n/. A língua não apresenta vogais fonologicamente nasais /i, i, e, o, a/, e o processo de nasalidade nessa língua é extremamente local, nasalizando apenas a vogal adjacente à esquerda da consoante nasal. Essa nasalidade tem um efeito fonético ou coarticulatório. Cohn (2007), ao descrever os padrões de coarticulação, observa similaridades com os processos de assimilação, uma vez que eles recebem uma mesma explicação. Porém, devemos compreender que os efeitos de coarticulação estão mais ligados à fonética, enquanto que, os de assimilação referem-se à fonologia.

A nasalidade nessa língua só é desencadeada por consoantes nasais que vai nasalizar às vogais que as antecedem. Contudo, como afirma Barbosa (1993), a ocorrência de nasalidade em vogais que estão próximas de uma consoante nasal não é sistemática, ou seja, nem sempre ocorre. Podemos verificar nos exemplos abaixo (3-c) que a nasalidade da vogal contígua a uma consoante nasal em Parakanã não é obrigatória e pode ou não ocorrer. A direcionalidade é predominantemente regressiva.

(1) Parakanã (GOMES, 1991, p. 32-46)
a. /paena/
$\left[\mathrm{pa}{ }^{\prime} \tilde{\varepsilon} \mathrm{na}\right.$
'cesto (variedade)'
b. /inata/
[ĩna'ta]
c. /mina/
[a'mĩna]
'coco de babaçu'
'chuva'

Diferentemente da língua Parakanã, a língua Mbyá apresenta dois tipos de gatilhos de nasalidade: consoantes nasais $/ \mathrm{m}, \mathrm{n}, \mathrm{y}, \mathrm{y}^{\mathrm{w}} / \mathrm{e}$ vogais fonologicamente nasais /̃̃, ̃̃, ũ, ẽ, õ, ã/. Foi verificado que o espalhamento de nasalidade nessas línguas é a longa distância, embora em alguns dados tenha um espalhamento local condicionado por uma consoante nasal. Todavia, em alguns exemplos foi mostrado que a nasalidade condicionada por $\mathrm{N}$ e também por $\tilde{\mathrm{V}}$ pode afetar outros segmentos compatíveis não adjacentes. As obstruintes /p, t, k ( $\left.\mathrm{k}^{\mathrm{w}}\right)$, ?, h, $\mathrm{g} /$ comportam-se como elementos transparentes, uma vez que elas não bloqueiam o processo. Então, os elementos alvos da nasalidade são vogais, glides e líquidas. A direcionalidade é predominantemente regressiva, ou seja, à esquerda. Os exemplos abaixo exibem a harmonia nasal em Mbyá.

(2) Mbyá (GUEDES, 1989, p.17-19)

2.1 Nasalização condicionada por vogais nasais subjacentes: Regressiva
a. /arukã/
[ã̃̃u' kã]
'costela'
b. /akãl
[ã'kã]
'cabeça' 

c. /awã/
[ãพ̃̃a]
'homem'

2.2 Nasalização condicionada por consoantes nasais fonêmicas: Regressiva
a. /ne reniwa/ [nẽ r̃ẽndi'wa]
'teu queixo'
b. /pino/ [pĩndo]
'palmeira'
c. /momiri/ [mõmbi'ri]
'longe'

Outro padrão de nasalidade encontrado é na língua Guajá, onde obstruintes bloqueiam o processo. A língua Guajá exibe $\mathrm{N}$ e $\tilde{\mathrm{V}}$ desencadeando a nasalidade. Os alvos são vogais, glides e líquidas. A nasalidade condicionada por $\mathrm{N}$ é local, uma vez que apenas nasaliza a vogal que a antecede, enquanto que a nasalidade desencadeada por $\tilde{\mathrm{V}}$ nasaliza toda a palavra, configurando-se em uma nasalidade a longa distância. A direcionalidade é predominantemente regressiva. Os exemplos em (4) exibem o padrão de harmonia nasal na língua Guajá.

(3) Guajá (NASCIMENTO, 2008, p.36-45)

3.1 Nasalidade desencadeada por vogais nasais fonêmicas: regressiva
a. /wihẽ/

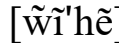
'semente'
b. /hawihã/

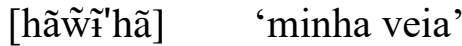
c. /i-parawã/
[ipãrã' w̃ã] 'umbigo dele'

3.2 Nasalidade desencadeada por consoantes nasais: regressiva
a. /pina/
[phĩna]
'anzol'
b. /tamanu?a/ [tãmãnu'?a]
'tamanduá'
c. /ame/
[n''me]
'apagar'

3.3 Espalhamento de nasalidade sendo bloqueado por obstruintes surdas
a. $/ \mathrm{ik}^{\mathrm{w}} \tilde{\mathrm{e}} /$
[i'k $\left.{ }^{\mathrm{w}} \tilde{\mathrm{e}}\right]$
b. /hajatĩ $/$
[haja'tว̃]
'vivo'
c. /apetẽ/
[ape'tẽ]
'minha garganta'
$\sim$ [abe'tẽ] 'respirei'

Diante dos exemplos acima podemos perceber que essas línguas mesmo sendo de uma mesma família linguística, apresentam diferentes padrões de nasalidade. Por exemplo, no que tange os elementos gatilhadores, apenas Parakanã exibe $\mathrm{N}$ como desencadeadora do processo, diferente de Mbyá e Guajá que apresentam tanto N quando $\tilde{V}$. Em relação aos segmentos alvos, as vogais orais são afetadas em todas as línguas, mas em Mbyá e Guajá, além das vogais, os glides e líquidas também assimilam o traço nasal quando uma vogal fonologicamente nasal desencadeia o processo de nasalização. As obstruintes são transparentes em Mbyá, mas em Guajá são elementos opacos. Desse modo, podemos considerar que a nasalidade em línguas Tupí-Guaraní exibe tanto similaridades quando diferenças o que contribuem para os estudos translinguisticos que 
se preocupa não apenas com as generalizações entre as línguas, mas sim suas diferenças. A Tabela 1 abaixo exibem os padrões de nasalidade encontrados nas três línguas da família Tupí-Guaraní.

Tabela 1. Padrões de Nasalidade em Mbyá, Parakanã e Guajá

\begin{tabular}{lllllll}
\hline Línguas & Gatilhos & Alvos & Transp. & Bloq. & Dom. & Direcionalidade \\
\hline Mbyá & $\mathrm{N}+\tilde{\mathrm{V}}$ & $\mathrm{V}, \mathrm{G}, \mathrm{L}$ & $\begin{array}{l}\text { Obstruintes } \\
\text { surdas }\end{array}$ & - & $\begin{array}{l}\text { A longa } \\
\text { distância }\end{array}$ & Regressiva \\
\hline Parakanã & $\mathrm{N}$ & $\mathrm{V}$ & & Local & Regressiva \\
\hline Guajá & $\mathrm{N}+\tilde{\mathrm{V}}$ & $\mathrm{V}, \mathrm{G}, \mathrm{L}$ & - & $\begin{array}{l}\text { Obstruintes } \\
\text { surdas }\end{array}$ & $\begin{array}{l}\text { Local } \\
(\mathrm{N}) / \mathrm{A}\end{array}$ & $\begin{array}{l}\text { Regressiva } \\
\text { longa } \\
\text { distância } \\
(\tilde{\mathrm{V}})\end{array}$ \\
\end{tabular}

Fonte: Autoras, 2018.

\subsection{Palatalização}

Discutiremos, neste momento, sobre o processo fonológico de assimilação, especificamente, de palatalização, bem como as bases da análise tipológica que aqui será realizada para este fenômeno. Como mencionamos no início dessa seção, o processo de assimilação pode ser local ou a longa distância. Esses dois tipos assimilatórios são encontrados em processos de palatalização. Para McCarthy e Smith (2003) a distância entre os segmentos alvos e engatilhadores pode diferenciar um processo de assimilação local (assimilação de lugar, de voz ou palatalização) de um processo de assimilação de longa distância (harmonia). Quanto à palatalização, McCarthy e Smith (2003) afirmam que, basicamente, consoantes seguidas de [i], [j] ou outras vogais anteriores assimilam a qualidade palatal das mesmas.

Em se tratando de palatalização, cabe esclarecer, primeiramente, a que se refere o termo palatal. Bateman (2007) explica que o termo "palatal" refere-se à região que se localiza desde atrás da parte alveolar até o final do palato duro do trato oral, incluindo, desse modo, as regiões alveopalatina e palatina. Com relação à palatalização, a autora a define como "qualquer instância em que uma consoante muda suas características de lugar para palatal, independentemente da natureza do gatilho, ou qualquer instância de uma consoante que adote uma articulação palatal secundária"2 (Bateman, 2007, p. 5).A

\footnotetext{
2 “(3) Operational definition of palatalization
} 
autora discute, então, dois tipos de palatalização: a palatalização plena e a palatalização secundária. Na palatalização plena, a consoante irá assimilar articulatoriamente, de maneira completa, a característica palatal de outra, já na palatalização secundária há apenas uma coarticulação da característica palatal sobre a consoante. A título de esclarecimento das denominações, cabe aqui ressaltar que a autora explica que o que ela denomina como palatalização secundária é tão somente palatalização para Clements e Hume (1996), e o que ela chama de palatalização plena é denominada por estes dois autores como coronalização.

No que concerne aos aspectos tipológicos, Chen (1973, apud BATEMAN, 2007) propõe uma hierarquia implicacional para os alvos do processo de palatalização. Segundo esta hierarquia, consoantes produzidas de modo mais anterior no trato vocal são mais propensas a sofrer palatalização, assim, seriam as dorsais as mais suscetíveis ao processo, seguidas das consoantes coronais e, por último, por consoantes labiais. Isto requer dizer, por exemplo, que se há palatalização de uma labial, logo as consoantes dorsais e coronais também são palatalizadas, ou, em outro caso, se há palatalização de coronais, então as dorsais também sofrem com o processo de palatalização. Do mesmo modo, o autor apresenta uma hierarquia implicacional para os gatilhos do processo de palatalização. O fenômeno é desencadeado, basicamente, por vogais anteriores e a hierarquia implicacional, neste caso, estará relacionada à altura das vogais, de modo que se as vogais baixas anteriores desencadeiam a palatalização, então as vogais altas anteriores também o farão. Outro segmento que se constitui como gatilho de uma palatalização, segundo Chen, é o glide palatal /j/, podendo ser, em algumas línguas, o único desencadeador do processo.

Bateman (2007) apresenta algumas considerações tipológicas sobre o processo de palatalização a partir da análise de 117 línguas. A primeira delas é que consoantes labiais nunca irão se palatalizar. A esse respeito, a autora afirma que palatalização plena de labiais é rara, estando relacionada a fatores históricos e estando restrita a dados contextos morfofonológicos. Na palatalização plena, as consoantes coronais e dorsais podem ser palatalizadas de modo independente ou junto tanto em contexto morfofonológico quanto somente fonológico. Já na palatalização secundária as consoantes dorsais podem ser palatalizadas somente de forma independente em contexto

- Any instance where a consonant changes its place features to palatal-like,regardless of the nature of the trigger.

- Any instance of a consonant acquiring a secondary palatal articulation.” (Bateman, 2007, p. 5) 
fonológico. Desta forma, Bateman (2007) discorda da hierarquia implicacional proposta por Chen (1973) e propõe outra: labial> coronal \& dorsal.

Com relação ao gatilho, Bateman (2007) afirma que o melhor segmento para desencadear a palatalização são as vogais altas anteriores, especificamente /i/. A respeito da hierarquia implicacional, a autora explica, quanto ao gatilho, se uma vogal baixa anterior funciona como gatilho da palatalização, então vogais altas anteriores também funcionarão. Da mesma forma, se uma vogal posterior ou central alta manifesta-se como gatilho da palatalização, então vogais altas anteriores também irão se manifestar como gatilho. Além disso, Bateman (2007) afirma que vogais altas posteriores só desencadeiam a palatalização, isto é, só funcionam como gatilho do processo, em consoantes coronais. Outra questão apontada pela autora é que o gatilho da palatalização geralmente segue o alvo, fazendo com que o processo ocorra de maneira regressiva. Por fim, ela discute que os gatilhos da palatalização geralmente são mantidos se são vogais, enquanto que se for um glide palatal, este provavelmente será excluído. A partir das discussões teóricas expostas, observaremos adiante, como ocorre o processo de palatalização em Línguas Indígenas da família Aruák e se as considerações tipológicas apresentadas neste tópico corroboram com o que ocorre nestas línguas.

\subsection{Discussões dos dados do processo de palatalização em Mehináku, Palikur e Paresi} (Aruák)

Trataremos, nesta seção, o processo de palatalização nas línguas da família Aruák: Mehináku, Palikur e Paresi. A língua Mehináku apresenta como gatilho do processo apenas a vogal alta anterior /i/ precedendo os alvos da palatalização, que são os segmentos /p, m, n, w, t, k/, como pode ser constatado nos exemplos a seguir:

(4) Mehináku (MORI, 2005, p. 1407-1409)
a. /pi-putaka/
[pipjutaka]
'tua aldeia'
b. /ji-maiki-ra/
[jimiãĩkira]
'milho de vocês'
c. /pi-neete/
[pinjẽ:te] [pijẽ:te] [pij̃̃̃:te]
'teu piolho'
d. /ji-wananai/
[ jijanãnãĩ]
e. /pi-tukunati/
[pitsukunãti]
'abraçadeira de vocês'
f. /ji-kalati/
[ jiffaluti]
'teu umbigo'
'lágrimas de vocês' 


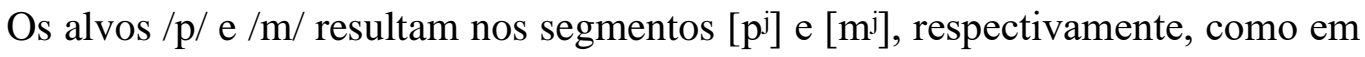
(6a) e (6b). A nasal /n/ pode manifestar-se com uma palatalização secundária [nj], como uma nasal palatal plena [n] ou ainda como uma aproximante palatal nasalizada [j] , como pode ser observado em (6c). Da mesma forma, após a vogal /i/, em fronteira de morfema, a aproximante /w/ também se palataliza plenamente, manifestando-se como [j], como observado no exemplo (6d), mas não sofre palatalização quando internamente na palavra, ainda que precedida ou entre a vogal /i/. Com relação às oclusivas /t/ e /k/, Mori (2015) afirma que elas passam pelo processo de palatalização após /i/, denominado por ele de assibilação, e manifestam-se como as africadas[ts] e [tg], como em (6e) e (6f). Segundo o autor, apesar de parecer que há condicionamento do ambiente para haver palatalização quando em fronteira de morfema, em razão da presença de /i/ no prefixo nominal de segunda pessoa (singular e plural), isto não procede, pois há dados em que o fenômeno ocorre na estrutura interna da palavra, comprovando que se trata de um processo mais geral na língua, como pode ser visto em Mori (2005, p.1410).

Outra língua Arawák que apresenta o processo de palatalização é a língua Palikur. Nessa língua ocorre a africação das alveolares /t/ e /d/ e a palatalização da nasal /n/ que, portanto, constituem-se como alvos do processo e originam, respectivamente, os segmentos [t],$\left[\mathrm{d}_{3}\right]$ e [n] (SILVA, 2016). Sucedendo os segmentos alvos, funcionam como segmentos engatilhadores do processo as vogais $/ \mathrm{i} / \mathrm{e} / \tilde{\mathbf{1}}^{/}$, conforme os exemplos abaixo:

(5) Palikur (SILVA, 2016, p.144)

5.1 Palatalização de /t/ e /d/ antes de /i/
a. /ipti/
[ip $\left.{ }^{\top} \mathrm{t} f \mathrm{i}\right]$
'banco, tamburete'
b. /tĩhaki/
[t đ̃̂háki]
c. /wadit/ [wadzit $\left.{ }^{\prime}\right]$ 'pranto, choro' 'reto'

5.2 Palatalização de /n/ antes de /i/ e /î/
d. /avakni/ [avak’ni]
'gavião'
e. /katiunĩ/ [katfiwjĩ]
'pagamento'

Já na língua Paresi a palatalização é engatilhada por /i/ ou /j/ precedendo os segmentos /b, $\varphi, \mathrm{w}, \mathrm{f}, \mathrm{d}, \mathrm{l}, \mathrm{m}, \mathrm{k}, \mathrm{h}, \mathrm{n} /$, que são, desse modo, os segmentos alvo. $\mathrm{O}$ resultado desta palatalização são, respectivamente, os fones $\left[b^{\mathrm{j}}, \phi^{\mathrm{j}}, \mathrm{w}^{\mathrm{j}}, \mathrm{d}^{\mathrm{j}}, \mathrm{l}^{\mathrm{j}}, \mathrm{m}^{\mathrm{j}}, \mathrm{k}^{\mathrm{j}}, \mathrm{h}^{\mathrm{j}}\right.$,

\footnotetext{
${ }^{3}$ Silva (2016) afirma que a consoante alveolar /d/ também é palatalizada diante de /î/, entretanto, não apresenta exemplos em sua análise.
} 
n],quando os alvos estão após a vogal /i/, como em (8.1), ou após o glide /j/, como em

(6) Paresi (SILVA, 2009, p. 141-145)

6.1 Palatalização engatilhada por /i/
a. /hibiabera/
[hibjiabere]
'teu papel'
b. /tiфati/
[ti $\phi^{\mathrm{j}}$ ati]
'jabuticaba'
c. /wiwahakanore $\theta \mathrm{a} /$
[wiw ${ }^{\mathrm{j}}$ ahakanore $\theta \mathrm{a}$ ]
'nosso macaco'
d. /kidane/
[kid ${ }^{\mathrm{j}}$ ane]
'pequeno'
e. /wilololiti/
[willololiti]
'brincadeira'

6.2 Palatalização engatilhada por $/ \mathrm{j} /$
a. /kajmare/
[kajm ${ }^{\mathrm{j}}$ are]
'lua'
b. /ajkuliti/
[ajk uliti]
'dente'
c. /majhã/
[majh ã]
'não'
d. /ajnakujta/
[ajnakujta]
'ele está voando'

Em contexto diferente dos demais segmentos, antecedendo a vogal /i/, os fonemas /ts/ e / $\theta /$ também sofrem palatalização, realizando-se, respectivamente, com [t] e [J], como nos exemplos em (8.3), vistos em Silva (2009, p. 149-150). Quando em fronteira de morfema e após a vogal /i/, a fricativa dental / $\theta /$ se manifesta também como [j] e / $\mathrm{t}^{\mathrm{j}} /$ se manifesta como [ts], o que pode ser observado em (8.4).

6.3 Palatalização de /ts/ e / $\theta$ / antecedendo a vogal /i/
a. /sikere/
[yik' 'amarelo'
b. /nukaja $\theta \mathrm{i} /$
[nukajafi] 'eu estou sujo'

6.4 Palatalização de / $/ \theta /$ e / $\mathrm{t}^{\mathrm{j}} /$ em fronteira de morfema após a vogal /i/
a. /hi- - Ootere /
[hijotere]
'vermelho'
b. /hi- $\mathrm{t}^{\mathrm{j}} \mathrm{O} /$
[hitso]
'você'

A partir do que foi apresentado acerca dos dados das línguas acima, discutiremos os resultados encontrados, com base em uma abordagem tipológica que demonstrará os padrões e singularidades do processo de palatalização nessas línguas indígenas, especificamente com relação aos segmentos engatilhadores, alvos e resultantes desse processo. Observa-se que as três línguas Arawák analisadas apresentam um padrão geral com relação aos segmentos que desencadeiam o processo de palatalização. Todas elas possuem como gatilho o segmento /i/, sendo que Paresi apresenta o glide palatal /j/ também desencadeando o processo. 
De todo modo, todos os segmentos engatilhadores são caracterizados como altos e anteriores, explicitando assim um primeiro padrão no processo de palatalização das línguas indígenas Arawák em questão e corroborando a afirmação de Bateman (2007) de que o melhor segmento para desencadear a palatalização são as vogais altas anteriores, especificamente /i/. Bateman (2007) encontrou em quatro línguas, durante sua análise, a vogal alta posterior engatilhando a palatalização, o que não foi atestado nessa pesquisa para nenhuma dessas línguas.

Como visto anteriormente, para Chen (1973, apud BATEMAN, 2007) consoantes produzidas de modo mais anterior no trato vocal seriam mais propensas à palatalização, o que implica dizer que as consoantes dorsais seriam mais suscetíveis ao processo. Entretanto, a pesquisa aqui realizada, demonstra que esta não foi uma tendência seguida pelas línguas Arawák. A língua Palikur, por exemplo, não apresenta nenhuma consoante dorsal que sofra o processo de palatalização, mas possui coronais que sofrem tal processo. Em Mehináku, quanto às consoantes dorsais, apenas /k/ é alvo deste processo, sendo Paresi a língua que possui a maior quantidade de segmentos dorsais comportando-se como alvos da palatalização, ainda assim trata-se de um número baixo, apenas $/ \mathrm{k} / \mathrm{e} / \mathrm{h} /$, se comparado à quantidade de segmentos coronais que funcionam como alvos.

Os alvos mais recorrentes nas três línguas analisadas foram os segmentos coronais. Mehináku e Palikur apresentaram, em comum, os segmentos /n/ e /t/ como alvos do processo de palatalização, sendo que em Palikur além destes dois há ainda a coronal alveolar /d/. Esta língua, apesar de apresentar em seu quadro de fonemas as consoantes dorsais /k/ e /g/, não demonstra o processo de palatalização nestes segmentos, possuindo, entretanto, as coronais /t/, /d/ e /n/ que sofrem este processo, como dito anteriormente. Desse modo, vê-se que as três línguas manifestam o processo de palatalização em consoantes coronais, mas Palikur, especificamente, refuta a hierarquia implicacional proposta por Chen (1973, apud BATEMAN, 2007), que diz que se há palatalização de coronais, então as dorsais também sofrem com o processo de palatalização, uma vez que a língua possui duas consoantes dorsais, /k/ e /g/, que não sofrem tal processo. Este resultado, portanto, corrobora a proposta de hierarquia implicacional proposta por Bateman (2007): labial> coronal \& dorsal. Por fim, a língua Paresi, dentre as três línguas, possui uma variedade de segmentos coronais que sofrem o processo de palatalização, quais sejam: /r, d/, /1/, /n/, /t $\mathrm{j} /, / \theta /, / \mathrm{t} /$. Os segmentos labiais também são afetados pela palatalização. Em Mehináku, tem-se /p/ e /m/ e em Paresi 
tem-se $/ \mathrm{b} /, / \varphi /$ e $/ \mathrm{m} /$ passando pelo processo. A língua Palikur é a única que não possuí labiais funcionando como alvo de palatalização.

Como discutido anteriormente, há dois tipos de palatalização: a palatalização plena e a palatalização secundária. Dentre as línguas analisadas, a única que apresentou apenas palatalização plena foi o Palikur.Em contrapartida, as línguas Mehináku e Paresi apresentam uma vasta manifestação de palatalizações plenas e secundárias. Em consonância à afirmação de Bateman (2013) de que a palatalização plena de labiais é rara, constatou-se que em todos os casos que havia labiais elas não apresentaram palatalização plena, apresentando somente palatalização secundária. Além disso, somente a língua Paresi apresentou palatalização de dorsais e do tipo secundária. A Tabela 2 sintetiza a distribuição das línguas com relação aos segmentos resultantes de palatalização plena (PP) e de palatalização secundária (PS).

Tabela 2. Tipologia da palatalização de Língua Arawák.

\begin{tabular}{ccccccc}
\hline & \multicolumn{2}{c}{ Labial } & \multicolumn{2}{c}{ Coronal } & \multicolumn{2}{c}{ Dorsal } \\
\cline { 2 - 6 } Mehináku & PP & PS & PP & PS & PP & PS \\
& & {$\left[\mathrm{p}^{\mathrm{j}}\right],\left[\mathrm{m}^{\mathrm{j}}\right]$,} & {$[\mathrm{n}] \sim[\mathrm{j}],[\mathrm{j}],[\mathrm{ts}]$,} & {$\left[\mathrm{n}^{\mathrm{j}}\right]$} & - & - \\
\hline Palikur & - & - & {$[\mathrm{t}],[\mathrm{d}],[\mathrm{n}]$} & - & - & - \\
\hline Paresi & - & {$\left[\mathrm{b}^{\mathrm{j}}\right],\left[\mathrm{m}^{\mathrm{j}}\right]$,} & {$[\mathrm{n}],[\mathrm{t}],[\mathrm{j}],[\mathrm{ts}]$} & {$\left[\mathrm{d}^{\mathrm{j}}\right],\left[\mathrm{l}^{\mathrm{j}}\right]$} & & {$\left[\mathrm{k}^{\mathrm{j}}\right],\left[\mathrm{h}^{\mathrm{j}}\right]$} \\
& & {$\left[\phi^{\mathrm{j}}\right],\left[\mathrm{w}^{\mathrm{j}}\right]$} & & & & \\
\hline
\end{tabular}

Fonte: Autoras, 2018

Em relação à direcionalidade do processo não foi possível estabelecer um padrão de manifestação, pois, cada língua se comportou de modo distinto. Na língua Mehináku a palatalização ocorre de modo progressivo, já em Palikur o espalhamento é de modo regressivo, e em Paresi pode-se constatar tanto a direção progressiva quanto a regressiva. A Tabela 3 abaixo resume os padrões de nasalidade encontrados em Mehináku, Palikur e Paresi.

Tabela 3. Padrões de Palatalização em Mehináku, Palikur e Paresi.

\begin{tabular}{llll}
\hline Línguas & Gatilhos & Alvos & Direcionalidade \\
\hline Mehináku & /i/ & $/ \mathrm{p}, \mathrm{m}, \mathrm{n}, \mathrm{t}, \mathrm{k}, \mathrm{w} /$ & Progressiva \\
& & & \\
\hline Palikur & $/ \mathrm{i} /, / \mathrm{i} /$ & $\mathrm{t}, \mathrm{d}, \mathrm{n} /$ & Regressiva \\
\hline Paresi & $/ \mathrm{i} /, / \mathrm{j} /$ & $/ \mathrm{b}, \varphi, \mathrm{m}, \mathrm{f}, \mathrm{d}, \mathrm{ln}, \mathrm{t}^{\mathrm{j}}, \theta$, & Regressiva/progressiva \\
& & $\mathrm{ts} /$ & \\
\hline
\end{tabular}

Fonte: Autoras, 2018. 


\section{Considerações Finais}

O presente artigo desenvolveu uma síntese da pesquisa tipológica, considerandoa como uma área bastante importante nos estudos das propriedades linguísticas das línguas do mundo. Vimos nesse trabalho que as pesquisas de tipologia são recentes na área de linguística e, em se tratando de tipologia fonológica, os estudos também são ainda mais incipientes, pois, como foi observado em Gordon (2016), as pesquisas em fonologia dentro da tipologia não são tão consolidadas quanto as pesquisas morfossintáticas. Em relação às línguas indígenas, esses estudos são bastante preliminares, apresentando algumas pesquisas em trabalhos acadêmicos (teses, artigos, dissertações etc.).

Nesse trabalho, utilizamos como exemplo dois processos fonológicos bastante frequentes em línguas do mundo: Nasalização e Palatalização. Observamos que em ambos os processos há segmentos que engatilham a nasalidade e aqueles que são afetados, ou seja, os alvos. Todavia, na nasalidade apresentaram-se também os segmentos transparentes e bloqueadores, que nesse caso são exclusivamente as obstruintes surdas (WALKER, 1998). Em relação à direcionalidade, tanto na nasalização quanto na palatalização predomina o espalhamento regressivo.

Em suma, esta pesquisa é apenas um esboço para apresentar alguns pontos importantes dos estudos tipológicos. Dessa maneira, buscou-se contribuir e ampliar informações sobre o fazer pesquisa em tipologia linguística, e, especificamente em tipologia fonológica. As pesquisas com línguas indígenas atualmente têm tido um avanço em diferentes abordagens linguísticas. Contudo, novos estudos ainda necessitam ser mais consolidados, como por exemplo, a tipologia fonológica, que ainda carece de pesquisas. Por isso, reforçamos cada vez mais que esses estudos ainda necessitam ser mais expandidos e descritos em trabalhos linguísticos referentes às línguas indígenas brasileiras.

\section{REFERÊNCIAS}

BARBOSA, José Natal. Contribuições à analise Fonológica do Suruí do Tocantins. 1993, 53 f. Dissertação (Mestrado em Linguística) - Universidade de Brasília, UNB, Brasília-DF, 1993 
BARNES, Jonathan. The phonetic roots of phonological typology: Final syllable vowels. In: MIT Speech Communication Group. Boston University: 2003

BATEMAN, Nicoleta. A Crosslinguistic Investigation of Palatalization. 2007, xxii, 340 f. Tese (Doctor of Philosophy in linguistics) - University of California, San Diego, 2007

BAKOVIĆ, Eric. Local Assimilation and constraint interaction. In: LACY, De Paul. The Cambridge Handbook of Phonology. Cambridge University Press, 2007, p.335-352. CLEMENTS, G. N; HUME E.. Internal Organization of Speech Sounds. In: The Handbook of Phonological Theory. 1996

CRYSTAL, David. Dicionário de Linguística e Fonética. Tradução: Maria Carmelita Pádua Dias.Rio de Janeiro: Jorge Zahar, 2000.

CROFT, William. Tipology and Universals.Cambridge Universaty Press: United Kingdon, 2002

COHN, Abigail C.A survey of the phonology of the feature [nasal]. Working papers of the Cornell phonetics laboratory, v. 8, p.141-203, 1993.

COHN, Abigail C. Phonetics in Phonology and Phonology in Phonetics. Working Papers of the Cornell Phonetics Laboratory, v. 16, 2007, p.1-31.

COHN, Abigail C.; RIEHL, Anastasia K. The Internal Structure of Nasal-Stop

Sequences: Evidence from Austronesian. In: Labphon11 abstracts. New Zeland: Paul, Warren, 2008.

GOMES, Ivanise Pimentel. Aspectos Fonológicos do Parakanã e Morfossintáticos do Avá-Guajá (Tupi). 1991, 85 f. (Dissertação de mestrado, Universidade Federal de Pernambuco. Recife. 1991

GORDON, Matthew K. Phonological Typology.Cambridge Universaty Press: United Kingdon, 2016

GREENBERG, Joseph H. The Tonal System of Proto-Bantu. The Tonal system of Proto-Bantu, 1948.

GREENBERG, Joseph H. Is the vowel - consonant dichotomy universal?, 1962.

GREENBERG, Joseph H. Vowel harmony in African languages. In: Actes du Second Colloque Internationale de Linguistique Negro-Africaine, p.33-38. Dakar: Université de 
Dakar, West African Languages Survey, 1963b.

GREENBERG, Joseph H. Language Universals. Berlim: W de G, 1963a.

GREENBERG, Joseph H. Synchronic and diachronic universals in phonology. Language. 1966.

GREENBERG, Joseph H. Some generalizations concerning glottalic consonants, especially implosives. International Journal of American Linguistics, 1970.GREENBERG, Joseph H, JENKINS, James J.; FOSS, Donald J. Phonological distinctive features as cues in learning. Journal of Experimental Psychology, 1967.

GREENBERG, Joseph H. Some generalizations concerning glottalic consonants, especially implosives. International Journal of American Linguistics, 1970.

GREENBERG, Joseph H.; KASHUBE, Dorothy. Word prosodic systems: a preliminary report. Working Papers in Language Universals 20.1-18. Stanford University, 1976.

GREENBERG, Joseph H. Some generalizations concerning initial and final consonant clusters.Linguistics, 1978.

GUEDES, M. Subsídios para uma análise fonológica do Mbyá. 1989. 50 f. Dissertação de Mestrado (mestrado em linguística) - Universidade Estadual de Campinas, Instituto da Linguagem, Campinas-SP

HAJEK, John. Vowel Nasalization. In: In: DRYER, Matthew S. \&HASPELMATH, Martin (eds). The World Atlas of Language Structures Online, 2013. Disponível em:http://wals.info/chapter/2. Acesso: 12 nov 2017

HYMAN, Larry M. How (not) to do phonological typology: the case of pitch-accent.In: Science Direct - Language Sciences. Berkeley: University of California, 2009.ok

HYMAN, Larry M. What is phonological Typology? Workshop on Phonological Typology. University of Oxford, Somerville College, p. 101-118, 2014

HAMMOND, M. Phonological Typology. Encyclopedia of Language \& Linguistics. Disponível em: http://www.sciencediret.com/science/article/pii/B0080448542000468. Acesso, 25 jun. de 2017.

KRAMER, Martin; UREK, Olga. Perspective on palatalization. Glossa: a journal of general linguistics 1(1): 31. p.1-17, 2016 
KORTVÉLYESSY, Lívia. Phonological Typology.In: Essentials of language Typology. Kosice, 2017. p.33-40.

LINDBLOM, Björn ; MADDIESON, Ian. Phonetic Universals in Consonant Systems. In: HYMAN, L.; LI, C. (eds), Language, Speech and Mind. London: Routledge, 1988. p. $62-78$

MADDIESON, Ian; PRECODA K. Phonological Segments Inventory Database (UPSID).Disponível em: http://web.phonetik.uni-frankfurt.de/upsid_info.html, 1988. A acesso em: 19 nov. 2017

MADDIESON, Ian. Patterns of sounds. Cambridge University Press, 1989

MADDIESON, Ian.Typology of Phonological Systems. In: HEINE, Bernd; NARROG, Heiko (eds). The Oxford Handbook of Linguistic Typology. Oxford; New York: Oxford University Press, 2010. p.xx-xx

MADDIESON, Ian. Vowel Quality Inventories. In: DRYER, Matthew S.; HASPELMATH, Martin (eds). The World Atlas of Language Structures Online, 2013. Disponível em: http://wals.info/chapter/2. Acesso: 12 nov 2017.

MOORE, Denny; et e al. Desafio de documentar e preservar línguas. Scientific American Brasil. v.3, p.36 - 43, 2008. Edição Especial

MCCARTHY, John J.; SMITH, Norval. Phonological processes: Assimilation. In: Oxford International encyclopedia of Linguistics. 2. ed., v. 3. Massachusetts: Oxford University Press, 2003.http://scholarworks.umass.edu/cgi/viewcontent.cgi?article=1019\&context=linguist _faculty_pubs. Acesso em: 21 jul. 2017

MORI, Angel Corbera. A palatalização de consoantes na língua Mehináku (Arawák). In: HORA, Dermaval da; PEDROSA, Juliene Lopes R.; LUCENA, Rubens M. (org.). ALFAL 50 ANOS: contribuições para os estudos linguísticos e filológicos. . João Pessoa: Ideia, 2015. p.1431 -1459

NASCIMENTO, Ana Paula. Estudo Fonético e Fonológico da Língua Guajá. 2008. 79

f. Dissertação de Mestrado (Mestrado em Linguística) - Universidade de Brasília (UNB)

- Programa de Pós-Graduação em Linguística, Brasília 
ODDEN, David. Phonological typology and naturalness. In: Introducing Phonology: (Cambridge Introductions to Language and Linguistics). Cambridge: Cambridge University Press, 2013. p. 225-256

RODRIGUES, Aryon. Línguas indígenas brasileiras. Brasília, DF: Laboratório de Línguas Indígenas da UnB, 2013. 29 p. Disponível em: http://www.laliunb.com.br>. Acesso em: 02/03/18

SILVA, Elissandra Barros da. A língua Parikiwki (Palikur, Arawák): situação sociolinguística, fonética e fonologia. 2016. 198 f. Tese (Doutorado) - Programa de Pós-graduação em Linguística. 198 f. Universidade Federal do Rio de Janeiro. Rio de Janeiro, 2016

SILVA, Glauber Romling da. Fonologia da língua Paresi-Haliti (Arawák). 2009, 319 f. Dissertação (Mestrado) - Programa de Pós-graduação em Linguística. Universidade Federal do Rio de Janeiro. Rio de Janeiro, 2009

SOUZA, Paulo Chagas de; SANTOS, Raquel Santana. Fonologia. In: FIORIN, José Luiz (org.). Introdução a Linguística: II. Princípios de análise São Paulo: Contexto, 2011.

VADJA, Edward. Test materials dated August, 17, 2001. Disponível em: http://pandora.cii.wwu.edu/vadja/ling201/test2materials/Phonology3.htm. Acesso em: 20/01/2017.

WALKER, Rache. Nasalization, Neutral Segments and Opacity Effects. (Doctor of Philosophy), University California, Santa Cruz, 1998.

WHALEY, Lindsay J. Introduction to typology: the unity and diversity of language. Califórnia: SAGE Publications, 1997 